\title{
Leadership and Values
}

\author{
Dr Anita Bhalla ${ }^{1}$, Mrs. Suman Dutt ${ }^{2}$ \\ ${ }^{1}$ Director Principal, ${ }^{2}$ PGT, English \\ Bharatiya Vidya Bhavan SL Public School, Amritsar, Punjab, India
}

\section{ABSTRACT}

Leadership is a virtue that elutes out of a character that is empowered by genetic make-up and environmental observations. A leader as somebody who is spiritually aware such that he can experience the intangible virtues of truth, goodness, beauty, love and compassion and can use the weapons of intuition, creativity, insight and focused attention towards achieving goals irrespective of the fact that they are predefined or not. A good Leader promotes a regaining of new outlook, confidence, zeal -and knowledge of right and wrong. One of the foremost duties that a leader has to fulfill is that he has to kindle in his followers a regaining of new outlook, confidence, zeal, and the knowledge of difference between the right and the wrong. But the question that props out is that can such kindling ignite into a ferocious fire all of a sudden? Can a person who never had an atmosphere enriched with aspirations of discipline and motivating goals, suddenly understand the concept of working in a team? One of the foremost ways via which a leader functions is his ability to communicate. A leader makes sure that every instruction that comes from him is clear and practical. In other words, goals may be bigger but targets should be short and step-wise. A leader doesn't hide his fears but rather he addresses them fearlessly and demonstrates ways of dealing with them. He brims his followers in the emotion of tirelessness and thrill such that no matter how cumbersome a task is, a follower dares to embrace it. A leader has to present herself as a supporter who can put a caring hand on her subordinates, who is not submissive or oppressive, who is kind and generous with ideas. A leader participates in the works he instructs others and occasionally showcases his own potential in yielding results. A leader begins a step in a project through his instruction but allows the followers to freely exercise their abilities. He monitors the subjects ardently but almost secretly and maintains notes. Throughout the study, it has been observed that leadership although is a virtue that is innate but it is also a quality that can be imbibed and induced in course of time depending upon the environment and circumstances. Even when it is the family that one encounters foremost, it is the school that officially begins the journey of inculcating such values. A country like India today needs efficient leaders and followers with leadership qualities. This is possible only through value-added education. Valueadded education is an education that comprises awareness of surroundings using latest equipment and the impartation of such knowledge is by spirited teachers headed by a well-organized and decisive Principal.

Key Words: LEADERSHIP, Communicative Abilities, Situation Analysis, Providing Opportunity, Presentation as a Supporter, His Own Involvement in the Working Process, Talent Identification, Garnering Feedback, Mentoring, Time Management

\section{LEADERSHIP: An Understanding}

Leadership is a virtue that elutes out of a character that is empowered by genetic make-up and environmental observations. History a subject that has transitioned from its importance as a record of dates to a gospel of observation and a research over many historical characters has summed up the definition of a leader. A leader as somebody who is spiritually aware such that he can experience the intangible virtues of truth, goodness, beauty, love and compassion and can use the weapons of intuition, creativity, insight and focused attention towards achieving goals irrespective of the fact that they are predefined or not.

The world of today is advancing at a pace that is unprecedented and almost daunting. The concept of 'Survival of the Fittest' that Darwin suggested long 
ago, seems most applicable today. Today, everything begins from competitions and ends with competitions. The matter is not merely about topping a chart of rankers but it also concerns the survival of a participant from the quagmires of depressions and a feeling of inferiority. This certainly ascertains the truth that the presence of leaders exhibit certainly more necessity than it ever before had.

One of the foremost duties that a leader has to fulfil is that he has to kindle in his followers a regaining of new outlook, confidence, zeal, and the knowledge of difference between the right and the wrong. But the question that props out is that can such kindling can ignite into a ferocious fire all of a sudden? Can a person who never had an atmosphere enriched with aspirations of discipline and motivating goals, suddenly understand the concept of working in a team?

Renowned psychologists and psychiatrists (Freud being one of them) have studied the working of brain at conscious, sub-conscious and dream-level. In the tomes of documents that they have published, the concepts have been so profound yet so truthful that the human society becomes astoundingly transparent. A human brain visualizes and observes everything consciously and subconsciously. It stores information in fragments and under certain triggering mechanisms, the fragments unite and form a pattern, we term as, "Idea". An idea may be a sudden occurrence but it crops out of every titbit of information that the brain has processed knowingly or unknowingly. But when researches were thrust open understanding how the phenomena of idea formation works, it was claimed that it is under the pressurized circumstances of an instructor (leader) or a relaxed state of sleep that a brain works out the mechanism of gluing the fractions of information into a complete piece. A.K. Banerjee wrote in his book named Art of Leadership that leadership is a process by which a person influences others to accomplish an objective and directs the organization in a way that makes it more cohesive and coherent.

Thus, the essentiality of a leader is indisputable and the fact that brain is the toughest animal to tame is uncontroversial. Since only a well-fed brain can work efficiently, it becomes of utmost importance that right from the schools and colleges, a child observes leadership qualities and decision-makers around him, for a child is like a flower that blossoms best when watered in the right amount under the righteous shade of sun.

Contrary to this, the unfortunate turn of events has brought mankind to the scenario when schools and colleges do not have leaders to impart knowledge and systematic learning to the pupils. The leaders in the countenance of teachers are actually losers who chose teaching as a profession either to earn easy-money or because the doors of other professions were shut for them. It is only at the point of being or becoming a Principal that a teacher realizes her leadership and responsibility and that too because unsaid tasks suddenly become said; this is when a Principal becomes a keen observer and a planner who manages a workforce and gets best out of her people. But sadly, even such an induced leader is obliged to stay away from the students, considering the herculean matters that a Principal has to resolve. The understanding that is imbibed from here is that although leadership commences at the post of a Principal, it has to travel down to the teachers so that the future-leaders (students) observe the traits of strength, decisiveness and confidence at every moment and shape up into beings of superior intellect and influence.

This is why the time of today asks for a lucid illustration that describes succinctly the definition of a leader, the exercises through which leadership can be induced on the teachers and inculcated in the students.

In simple words, a leader is someone who is aware of his strength and limitations, who understands his qualities and has a clear yet honest understanding about his personality. A leader at any post has to understand that his success is determined by his followers and not by himself; A leader has a clear understanding about human nature, aspirations, sentiments, emotions and thinking. A follower on the other hand is someone who follows the leader many a times with blind faith; A faith that effortlessly accumulates in a follower when the leader is wellread, well-learned and well-experienced.

\section{THE WAY A LEADER FUNCTIONS Communicative Abilities}

One of the foremost ways via which a leader functions is his ability to communicate. A leader makes sure that every instruction that comes from him is clear and practical. In other words, goals may be bigger but targets should be short and step-wise. For instance, a simple act of school-homework becomes ginormous 
when a teacher aims at astounding the students with her claims of how difficult the subject is. A teacher as a leader needs to simplify her instruction and give students a targeted approach that they can positively accomplish. Besides, the role of a leader turns into that of a coach because by the means of his speech, a leader motivates. Such a motivation is termed as 'Verbal Motivation', which dispenses out of a speech that has fluctuating tone and interesting vocabulary. In such a way, a leader has to possess effective communicating skills.

\section{$>$ Situation Analysis}

Nature works on a free flow of energy and every circumstance is formed of a different set of energy molecules such that the judgement has to be different for different situation. Acknowledging such variation, a leader has to understand that although his role always remains the same but his styles have to be changed incessantly. The role of a leader as a motivator and opportunity-provider stays the same but his style of imparting such morals in the followers can differ from situation to situation. A leader doesn't hide his fears but rather he addresses them fearlessly and demonstrates ways of dealing with them. He brims his followers in the emotion of tirelessness and thrill such that no matter how cumbersome a task is, a follower dares to embrace it. Once again, taking teacher as an example, the concept can be elucidated. An educational life is deluged with tournaments, competitions and examinations. A teacher as a leader alters his style of assessing the information but sticks to his role of a motivator and opportunity-provider.

\section{$>$ Providing Opportunity}

A leader understands that the success of his team depends upon the individual successes of his teammembers. Successful people comprise a successful team and failed individuals do not make a successful team. Therefore, in the initial stages of teamformation, a leader studies the abilities of every member of his team and dispenses opportunities suitable an individual's growth - thus rigidifies the team as a whole and sharpens the skills of his teammembers towards envisioning a problem with their own set of sharpened skills each. A class-teacher for instance, is well-aware of the tendencies and capacities of her students. She renders it by studying the performance of every roll-number in different subjects and spends a separate time individually with every student to address the latter's concerns and aspirations. She also makes aware the parents of every student about the intellect and skills of their child so that the act of sharpening the dexterity pummels up either through extra-classes or field-trips. Then when the time needs it, a class-teacher can dissipate selected tasks to selected students and along with encouraging them, build up an atmosphere that is healthy and result-oriented.

\section{$>$ Presentation as a Supporter}

A human being is a sensitive creature. He senses things deeply and interestingly, a mentally-wreck individual also makes certain decisions. As discussed earlier, a leader is supposed to provide his subordinates with understandable instructions and apart from that a leader must not portray himself as a immaculate creation of nature that cannot be duplicated no matter how hard the follower tries. Since a human by nature runs away from undoable things, such a portrayal would turn him off from the zeal with which he began his work. A leader has to present herself as a supporter who can put a caring hand on her subordinates, who is not submissive or oppressive, who is kind and generous with ideas. Although, personal questions are impolite, a leader makes sure that he creates an understanding relation with his followers by narrating his personal experiences; thereby portraying himself humanly.

\section{His Own Involvement in the Working Process}

Rome was not built in a day and nor was it created single-handedly. A leader participates in the works he instructs others and occasionally showcases his own potential in yielding results. Such acts build an air of trust among the followers. Moreover, dedication is the only attribute that a leader is supposed to portray and the portrayal should impart the only message that everything the leader has achieved has been because of his dedication; nothing supernatural or god-gifted about it. He should affirm that every member of the team has god-gifted qualities and thus more than qualities, dedication matters.

\section{VALUES OF A LEADER: A special concentration over Educational Institutions \\ $>$ Talent Identification}

In the start of every project, a leader has to vividly demarcate the issues and objectives the completion of the project has to achieve. Following this, a step-wise plan has to be constructed wherein the adequacies of the prevalent team and requirement of specific new talents are addressed. This follows the interview 
rounds where out of all the participants, irrespective of background and other discriminations, the talent alone is hunted for. A Principal in a school for example, hires teacher trained for specific subjects and many a times hires trainees and coaches for particular knowledge considering merely the experience and not the qualifications. Statistical information derived from various hiring institutions reveal that many a times, raw talents are hired since more than the talent, potential was evident in the interviewee. This potential clearly spoke on how the talent would develop with experience and the raw individual would turn into an asset.

\section{$>$ Garnering Feedback}

The virtue of strength accounts for the sum-total of adaptability, receptivity and adherence. A leader showcases such qualities and he achieves this by garnering feedback from the people connected directly with the project and from those connected indirectly. He focuses on a specific target so intensely that no matter how varied and deviated the feedbacks were, he measures them on the measuring scale of his gut-feeling and discusses the issues blatantly with his team-members. This strengthens his relation with the members of the team and enlightens him about his progress apart from bettering his approach. A teacher for instance tries to make her lecture as interesting as possible. She includes activities and tasks in her lecture to assure the interest of the student and in the later stages takes a test that describes clearly the skills that her lecture has developed in the student and the weak-areas where she has to focus on.

\section{$>$ Mentoring}

Every success is about embarking on an untested pathway with an idea that cropped out of a sudden moment. A leader begins a step in a project through his instruction but allows the followers to freely exercise their abilities. He monitors the subjects ardently but almost secretly and maintains notes. At later stages, he mentors his subjects by dissipating his beliefs and ideas and beaconing them towards a potentially better path. It so happens that a doer cannot be an observer of his doings. Because of this, an action-doer gets so involved in the task that he becomes incapacitated to understand the requirements and ways to deal with the hurdles. It is due to mentoring that such hurdles can be seen in a light of greater clarity. For instance, a maze looks bothersome when one is in it. The clarity of a maze increases when one sees it as an observer from a great height.
Another significant part of mentoring is the exercise in which experienced people interact with inexperienced people. It such happens that during field-trips or seminars, when students meet people working at a specific height and post, they either become invigorated or impassioned to embark upon a similar path. Apart from that, the biographies and stories of real people that a teacher discusses in the class highlights the mental adequacies and confusions of a great man during his youthful years and students on hearing such stories related themselves with such great men and therefore, not only feel impassioned but consider themselves an essential part of the working world where they begin thinking that their efforts would matter.

\section{Such activities also come under mentoring.}

A melancholic sign of a working team is a melancholic leader who complains and is himself discouraged. To make sure that such a depressive countenance doesn't appear on a leader, he should occasionally involve in social gatherings concerning such people because much higher should be the zeal of the leader such that it never ends no matter how much he distributes.

\section{Coaching, Training and Counselling}

Researches around the world in major sporting events and athletic organizations have distinctly affirmed that a sportsman performs better when in competition and when the focus of his training has been on the technical part i.e. the techniques required to enhance the performance rather than theoretical exercises.

A leader studies the opponents and the environment the act has to be performed in before sliding into the journey. He underlays the plans and machinations that he might follow and taking note of these, bucks up and buckles up the participant he has to train. For instance, in the preparation of competitive examinations, along with the basic knowledge of the subject, short-cut techniques and specially devised formulas work more effectively than merely the knowledge of the subject. Such a coaching is termed as full-fledged training.

As far as counselling is concerned, it includes thinking, implementing, knowing human nature, timing, sincerity, compassion and kindness. A.K. Banerjee has highlighted these specific qualities that a leader must possess. Foremost among them is 
'Respect for Employees', which is a belief that individuals are responsible for their own actions and ideas. An employee or follower should have faith on his unique value, attribute and skill but he should trust his leader understanding the fact that his skills would express super-most if channelled under his respective leader.

Interestingly, a leader must also know his biases because the more he understands his innate habits, the more he will try not to project them easily. If a leader is aware of his biased nature then he can veil it under the virtues of compassion and empathy. Such compassionate and empathetic dealings with the teammates counsel the workforce towards a series of spirited actions that lead to achievement.

\section{Time Management}

Considering the milling crowds of today, the topmost attribute possessed by a leader is Time Management. A leader has to understand the preciousness of time because even during his leisure time, the fragments of information he imbibed while working would integrate and generate an idea. Therefore, no matter what heading the time falls under - leisure or appointments or physical exercise or work, a leader demarcates his meetings and announces his firmness showing a slightly helpless expression; designating the time frame as crucial. This attracts respect for him and in an uncanny way poses him almost as inspirational.

There are various steps in Time Management:

1. Planning: In this step, goals are set.

2. Assessment: At this moment, the assessment of how the time is being utilized presently is done and accordingly, productive changes are made.

3. Organize: Following assessment, the tasks to be accomplished per day are highlighted and a timetable is formed for an entire week or month or even year as required for the work.

4. Prioritization: All tasks are prioritized systematically. More urgent things are kept on the top and less importantly committed works at the bottom. Here it is to be noted that some people prioritize difficult works first and leave the easier works for the later stages. The latter approach is usually followed when the time-table is fixed daywise. Under such a daily based time-table, since the energy is maximum in the morning, difficult tasks are placed then while as the sun begins setting, easier tasks are reproached.
In an educational organization where there are various departments and expectedly, every teacher is a leader, it becomes the duty of a Principal to organize conferences and meetings where an eye is kept on the steps that the teachers are taking. Essentially, a Principal encourages a teacher to plot a proper mechanism of completing the given task right from the initial stages.

\section{$>$ Creativity and Innovation}

In the words of Christopher Morley, "Read everyday something no one else is reading. Think everyday something no one else is thinking. It is bad for the mind to be always part of unanimity." Although maintaining the time-table is the foremost task of a leader, an efficient leader keeps some space in the schedule for experimentation. He understands that experimentation requires creativity and it is only through experimentation that innovation is encouraged. Following the words of Christopher Morley, a mind has to be fed and nourished with readings and thoughts and a human has to inspire his mind to think out of the box. This can be achieved by constant questioning on the part of the leader and even the followers. Robin Sharma has spoken some wonderful words, "Nourish your imagination and flex your mind. Let your natural creativity out of the box; Dare to dream bigger dreams and envision a higher future. Never forget that deep within the body of every visionary loader lives the spirit of a little child, full of excitement and wonder!" This creates an urgent need of an education system that is satisfactory, which can happen if the aim of education is the balanced growth of the individual and a system that insists on both knowledge and wisdom. Teacher of the teachers, Dr. Radha krishnan has said that education should not only train the intellect but should bring grace into the heart of the man.

It has to be understood that we do not always learn formally. We learn daily from out home, from our community, from the press, the radio, the television and the films. Dr. Radha krishnan also believed that an individual learns from his teachers, by himself and from others, from life and experience. An education doesn't have to be merely broad. It has to be deep and thorough. In the words of a great man, it should help an individual overcoming the beast within himself. Leaders thus have to provoke an atmosphere of freedom of mind and spirit. 
The discussion started with the concept of how teaching as a profession was not the first choice of the teachers in practice today and on a sad note we understood how because of such forcibly given choice of profession, the teachers do not portray themselves as efficient leaders and thus definitely do not nurture the leadership qualities in the students. We also understood how the principal who is at the topmost post where she has been chosen by circumstances is the only expected leader but unfortunately she cannot make herself available to students and thus cannot inspire leadership as freely as a teacher can. But as a side note although equally essential, it has been researched that leadership as a virtue is contagious. The supreme capacity, decisiveness and boldness of a Principal can influence the teachers in a way that leadership can be induced powerfully on the latter and from then on can further be induced upon the students.

\section{HOW CAN THESE VALUES BE IMBIBED?}

\section{Family}

It is the family that a child confronts before entering the official educational environment. The first observations and first expression are observed in the family and this is where an individual confronts the need of bearing leadership qualities. Evidentially, it has been seen that children born in troubled families where fathers are violent often begin taking life for granted and the entire zeal for leading a situation and achieving something productive is died out in them. The reason is that the first bit of that tiny motivation is provided at home when parents affirm their faith in their child, when parents acknowledge the little achievements of their child and entrust him with freedom that he can do what he may, for he is responsible.

\section{School}

Highlighting majorly throughout the essay is the concept that a Principal, the teachers and the classmates combine together to trigger leadership values in an individual. Teachers bearing flaccid attitude, unchecked and bullying classmates or a pointlessly strict Principal can negatively influence a child, plucking out any seed of leadership from him.

\section{$>$ Religion}

The aim of religion is to provide a sense of protection to a follower and to assure him that he is born for a reason. A religion clearly mentions that a human being has to serve the planet with productive actions.
Therefore, teachings of religion as a guide and merely as a story (Hinduism for instance is composed of scriptures and gospels deluging with fables and parables. Preachers often begin entertaining the learners via stories and avoid telling the real meanings of the stories.)

\section{Teaching Environmental Science}

Subjects apart from Mathematics and Science like Social Studies, Physical Education and Environmental Education educates a child or a learner about the surrounds he lives in and the body he owns. It makes him aware regarding how all beings are mutually connected in one or the other way by visible phenomena like food-cycle or invisible phenomenon like energy-cycle. This instantly insinuates a sense of responsibility - the first quality of being an efficient leader in him. Similarly Art Education promotes appreciation, coherence, thoughtfulness and serenity while History teaches them the values of unity, liberty and fraternity.

\section{$>$ Education Aids and Group Activities}

One of the most effective ways of imparting leadership values in a child is through educationalaids like use of advanced equipment and infrastructure. These things familiarize the futureleader with the working of the real world so that even outside the walls of school, a student feels at home and can think rationally. Consecutively, the practices of group-songs, prayers, school's pledge, Thought of the Day and National Anthem for example apart from competitive activities like Poetical Recitation, Declamations, Debates, Quizzes and Essay Writing competitions stark an atmosphere of leadership around.

\section{Parent-Teacher interaction}

Children observe the behaviour of their parents and teachers. They judge their capabilities by the remarks of the teachers and the way parents accept those remarks. They form an image about themselves by the way teachers and parents conclude their personalities.

\section{$>$ Rewards}

Giving rewards like medals and prizes not only for the intellectual achievements and sports but also for virtues like honesty, truthfulness, love, compassion and bravery. These motivate award-winners to adhere to these virtues for life. 


\section{CONCLUSION}

Throughout the study, it has been observed that leadership although is a virtue that is innate but it is also a quality that can be imbibed and induced in course of time depending upon the environment and circumstances.

Even when it is the family that one encounters foremost, it is the school that officially begins the journey of inculcating such values. A country like India today needs efficient leaders and followers with leadership qualities. This is possible only through value-added education.

Value-added education is an education that comprises awareness of surroundings using latest equipment and the impartation of such knowledge is by spirited teachers headed by a well-organized and decisive Principal.

Following are the outcomes that can be achieved by such value-oriented education:

$>$ Better academics achievement

$>$ Behaviour modification and disciplined attitude

$>$ Development in the interpersonal skills which involve social skills, awareness etc.

$>$ Development of intrapersonal skills resulting in the enhancement of self-confidence and selfesteem.

Harmonious growth of society and many more.

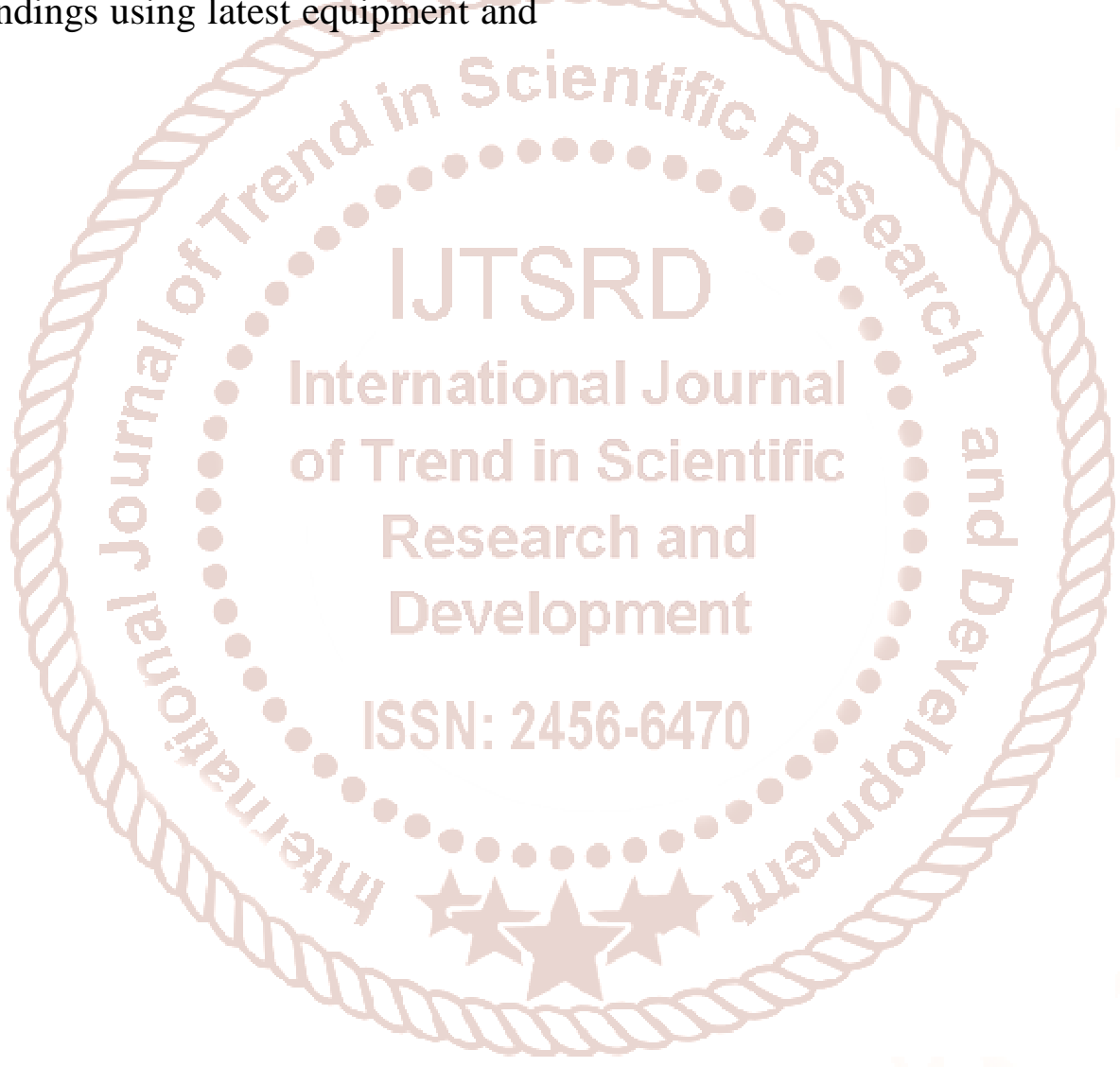

